\section{Tonic immobility as a reaction to predation: Artificial eyes as a fear stimulus for chickens*}

\author{
GORDON G. GALLUP, JR., RICHARD F. NASH \\ and ALTON L. ELLISON, JR. \\ Tulane University, New Orleans, La. 70118
}

Young habituated chickens exposed to artificial eyes suspended overhead remained immobile in response to manual restraint appreciably longer than did controls and were more susceptible to immobility. The results were discussed in relation to a defensive-distance dimension and in terms of the notion that tonic immobility may have evolved in response to predation.

The tonic immobility or hypnotic reaction to some form of manual restraint appears to qualify as an innate response (Ratner, 1967) which has been shown to be present in many insects, fish, reptiles, birds, and mammals. A recurring interpretation of the response, prompted in part by Darwin's (1900) discussion of death feigning, has been that it may represent a fear reaction which evolved as a result of selective pressure exerted by predation.

A recent proponent of this view has been Ratner (1967). He hypothesizes that responses to a predator or threatening stimulus vary as a function of the defensive distance between an animal and the source of stimulation. For example, when detection first occurs, the animal typically becomes alert and freezes, while, as the distance decreases, flight and escape responses are made. If the distance continues to diminish and physical contact either occurs or is about to occur, then the victim characteristically attempts to fight; finally, under conditions of zero distance accompanied by physical restraint, an immobility reaction ensues. The function of immobility could relate to the fact that predatory behavior for some animals may, in part, be dependent on stimulation arising from responses of the victim, e.g., that certain captive predators will eat only live food is an illustration of this point. Thus, the response of becoming immobile could serve to attenuate stimulation for further attack and, assuming a genetic basis for the behavior, could have evolved by virtue of its survival value.

Within this framework, Gallup, Nash, Donegan, \& McClure ${ }^{1}$ found that in the presence of a stuffed Cooper's hawk (Accipiter cooperri) young habituated chickens subject to manual restraint remained immobile significantly longer than birds not exposed to the hawk. Moreover, it was found that by either covering the hawk's head or by placing small pieces

*We wish to thank Martin S. Waite for photographic assistautce. of black plastic tape over the hawk's eyes, a threefold reduction in the duration of immobility could be achieved, suggesting that a predator's eyes are of considerable importance by way of sustaining the immobility reaction. In support of this conclusion, Gallup, Cummings, \& $\mathrm{Nash}^{2}$ found that, if a human $\mathbf{E}$ maintained eye contact with chickens during an immobility episode, a dramatic increase in the duration of the response could be reliably obtained relative to birds confronted with an $\mathbf{E}$ who avoided making eye contact.

The present study was run in an attempt to evaluate further the effect of eyes on immobility reactions in chickens through the use of artificial eyes.

\section{EXPERIMENT 1}

The first experiment was designed to assess the effect of suspending brownish-glass eyes over habituated chickens on the duration of self-paced immobility reactions in response to manual restraint.

\section{Subjects}

The Ss consisted of 30 Production Red chickens (Gallus gallus) obtained from a local hatchery at 2 days of age. All birds were housed in commercial brooders and received approximately $14 \mathrm{~h}$ of natural and artificial light per day. During rearing, the animals were given continuous access to Purina Chick Chow (Growena) and water. Apparatus

$T$ he apparatus consisted of a three-sided induction box, used to eliminate extraneous visual cues, mounted on a table in a separate experimental room. A pair of brown-colored glass eyes (see Fig. 1), measuring approximately $2 \mathrm{~cm}$ in diam, were mounted on the end of a pair of wooden dowels which were inserted into holes in a wood plank. During testing, the plank was placed across the top of the induction box, thereby suspending both eyes directly over the chick. Indirect lighting was provided by a $100-W$ bulb, and Hunter Klockounter timers (Model 120A), wired to silent single-throw switches, were used to record the duration of each immobility reaction. Large cardboard boxes were used to transport chickens to and from the experimental room and as pre- and posttest holding containers. Procedure

At 2 weeks of age, each bird was fitted with plastic leg bands for purposes of identification. Prior to testing, all birds were required to reach a habituation criterion. Habituation procedures were implemented after the chicks were 3-4 weeks of age and consisted of manually restraining a chick on its right side for $15 \mathrm{sec}$, with five trials being administered each day. To insure for a low level of responsiveness, the criterion for testing consisted of remaining immobile for no longer than $60 \mathrm{sec}$ on the first habituation trial for 2 consecutive days.

Upon reaching criterion, each bird was assigned randomly to one of two groups and then restrained laterally once more for $15 \mathrm{sec}$ under the appropriate test condition. For chicks in the experimental group, the glass eyes were suspended about $7 \mathrm{~cm}$ from the S's head during the restraint period and remained in that position for the duration of the immobility episode. The resulting immobility reaction was timed from the point manual restraint was terminated until the chicken rose to its feet or until $900 \mathrm{sec}$ had elapsed, in which case the response was terminated by the $E$ in the interest of economy of time.

Animals in the control group were treated identically, except that the eyes were absent and birds were confronted with only the bare dowels protruding from the board placed overhead on the test trial. Results

Exposure to glass eyes provided for a much more durable immobility reaction. Chickens confronted with brown eyes on the test trial remained immobile over six times longer than those simply exposed to the dowels (see Fig. 2). A one-way analysis of variance run on these data showed that the effect of eyes, by way of prolonging the immobility reaction, was statistically significant $(F=12.52$, df $=1 / 28, p<.005)$.

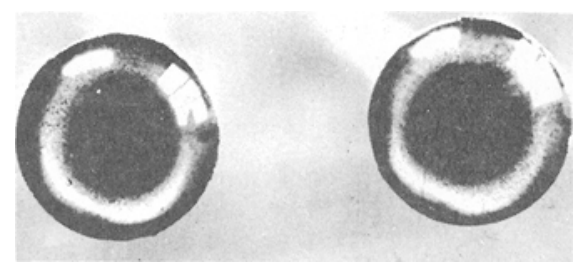

Fig. 1. Photograph of artifical brown eyes mounted on the wooden dowels. 


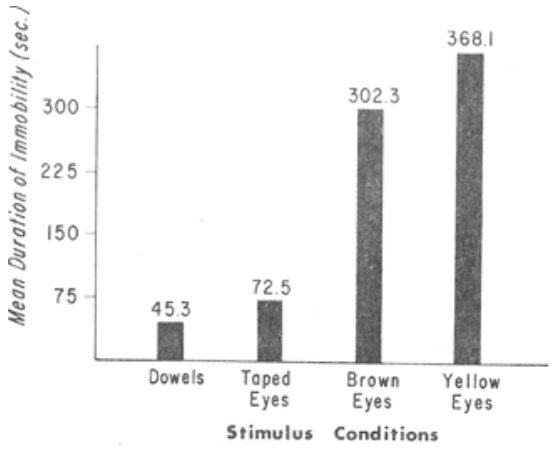

Fig. 2. A composite of the average duration of immobility for both experiments as a function of the type of stimuli in effect during the test trial.

Susceptibility to immobility was also enhanced by confrontation with the artificial eyes. On the test trial, only $53.3 \%$ of the chickens exposed to the suspended dowels for the first time became immobile in response to $15 \mathrm{sec}$ of manual restraint, while all birds in the experimental group showed the reaction. The Fisher exact probability (Siegel, 1956) for this difference was significant $(p=.003)$.

\section{EXPERIMENT 2}

Since the first experiment found a substantial difference between eyes and bare dowels, a second experiment was run with different colored eyes and included a supplemental control group confronted with eyes which had been covered with black plastic tape. The additional control group was included by way of an attempt to replicate the reduction in durability of immobility obtained by Gallup et al when the hawk's eyes were obscured. Method

The Ss were 30 additional Production Red chickens obtained and maintained similarly to those used in the previous experiment.

The apparatus and procedure was the same as that employed in the first experiment, except that comparably dimensioned yellow eyes with black pupils (see Fig. 3) were used for the experimental condition and eyes covered with black plastic tape were used for the control

\section{Results}

The results of the second experiment were comparable to those obtained in the previous study.

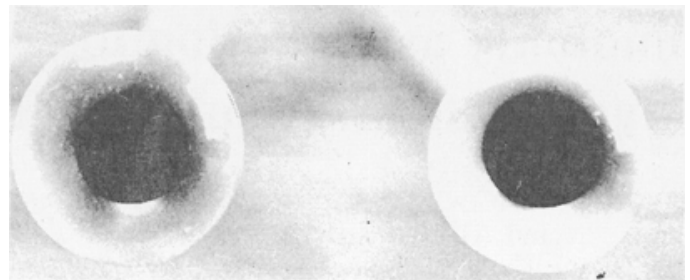

Fig. 3. Photograph of the yellow glass eyes attached to wooden dowels.

Habituated chicks exposed to the yellow eyes remained immobile over five times longer than those exposed to eyes covered with tape (see Fig. 2), and this difference proved to be statistically significant $(F=12.49$, df $=1 / 28, p<.005$ ).

Susceptibility to immobility also appeared to be reduced by placing tape over the glass eyes. On the test trial, $26.7 \%$ of the birds in the control group failed to show the immobility reaction, while all of the chicks exposed to the yellow eyes became immobile on the first trial. The Fisher exact probability for this difference was significant $(\mathrm{p}=.049)$.

\section{DISCUSSION}

In a now classic study of mimicry, Blest (1957) demonstrated that various eye-spot patterns on the wings of Lepidoptera have aversive properties for a number of birds which prey on these insects. Since previous studies (e.g., Gallup, Nash, \& Brown, 1971; Gallup, Nash, Potter, \& Donegan, 1970) have shown that the application of procedures designed to either increase or decrease fear reliably affect the immobility response, these data augment those of Blest in showing that, for chickens, eye patterns probably derive their aversive component by way of eliciting a fear reaction.

In the present study, the effect of artificial eyes alone was comparable to that produced by exposure to a chicken hawk, with habituated birds in both cases remaining immobile in excess of $300 \mathrm{sec}$ and showing evidence of enhanced susceptibility to immobility. Also of interest is the fact that placing black tape over either the glass eyes in the present experiment or over the hawk's eyes in previous work had the same effect, namely, an obvious reduction in both the durability and susceptibility to immobility. Along with Blest's data, these results imply that the fear-producing properties of simulated eyes are contextually independent of other facial and/or bodily features of potential predators.

In addition, a striking difference between experimental and control birds in both the present experiments was observed in terms of postimmobility reactions. The majority of birds confronted with the glass eyes showed intense escape reactions, with attempts to attack the $E$ and fly out of the induction box immediately following self-paced termination of immobility, while control Ss appeared quite passive and undisturbed after recovery from the immobility episode. This raises the intriguing possibility of a natural progression back through Ratner's (1967) hypothetical series of prey responses following a predatory encounter.

BLEST, A. D. The function of eyespot patterns in the Lepidoptera. Behaviour. 1957, 11, 209-256.

DARWIN, C. A posthumous essay on instinct. In G. J. Romanes (Ed.), Mental evolution in animals. New York: Appleton, 1900. Pp. 353-384.

GALLUP, G. G., JR., NASH, R. F., \& BROWN, $c$. W. The effects of a tranquilizer on the immobility reaction in chickens: Additional support for the fear hypothesis. Psychonomic Science, 1971, 23, 127-128.

GALLUP, G. G., JR., NASH, R. F. POTTER, R. J., \& DONEGAN, N. H. Effect of varying conditions of fear on immobility reactions in domestic chickens (Gallus gallus). Journal of Comparative \& Physiological Psychology, $1970,73,442-445$.

RATNER, $S$. C. Comparative aspects of hypnosis. In J. E. Gordon (Ed.). Handbook of clinical and experimental hvpnosis. New York: Macmillan, 1967. Pp. 550-587.

SIEGEL, $S$. Nonparametric statistics for the behavioral sciences. New York: MeGraw-Hill, 1956.

1. Gallup, Nash, Donegan, \& McClure, in preparation.

2. Gallup, Cummings \& Nash, in preparation 